\title{
PENENTUAN AKAR-AKAR PERSAMAAN NONLINIER DENGAN METODE ITERASI BARU
}

\author{
JAPILUS SAPARI, SUSILA BAHRI \\ Program Studi Matematika, \\ Fakultas Matematika dan Ilmu Pengetahuan Alam, Universitas Andalas, \\ Kampus UNAND Limau Manis Padang, Indonesia, \\ math.sapari@gmail.com
}

\begin{abstract}
Abstrak. Dalam makalah ini akan ditunjukkan bagaimana menyelesaian persamaan nonlinear $f(x)=0$ dengan menggunakan Metode Iterasi Baru. Untuk beberapa kasus melalui penggunaan Maple terlihat bahwa solusi persamaan non linier dengan Metode Iterasi Baru yang merupakan hasil dari subsitusi Metode Steffenson terhadap Ekspansi Taylor, konvergen ke solusi eksak.

Kata Kunci: Metode Newton, Formula Iterasi, Metode Steffenson, Ekspansi Taylor
\end{abstract}

\section{Pendahuluan}

Persamaan nonlinier banyak digunakan dalam bidang teknik maupun sains. Secara umum, persamaan dalam bentuk ini dapat diubah dalam bentuk $f(x)=0$ dengan $f$ merupakan bentuk fungsi nonlinier dari variabel $x$. Persamaan-persamaan nonlinier dengan bentuk $f(x)=0$ dapat diselesaikan secara analitik maupun secara numerik. Kedua cara penyelesaian tersebut ditujukan untuk memperoleh nilai dari $x$ pada persamaan $f(x)=0$ yang merupakan akar-akar dari persamaan tersebut. Berbagai cara atau metode numerik dapat digunakan untuk menyelesaikan persamaan nonlinear dalam bentuk $f(x)=0$. Diantara metode yang sering digunakan adalah Metode Newton.

\section{Beberapa Definisi}

\subsection{Persamaan Nonlinier}

Jenis-jenis dari persamaan nonlinier diantaranya:

(1) Persamaan Aljabar.

Persamaan aljabar yang termasuk dalam persamaan nonlinier adalah persamaan dalam bentuk:

(a) Polinomial (Suku Banyak) adalah polinomial atau suku banyak satu variabel secara umum dapat dinyatakan sebagai berikut:

$$
f(x)=a_{0}+a_{1} x+a_{2} x^{2}+\ldots+a_{n} x^{n}
$$

dimana $a$ adalah konstanta. 
(b) Persamaan Rasional adalah persamaan rasional adalah persamaan yang dapat ditulis dalam bentuk $p(x)=q(x)$, dimana $p(x)$ dan $q(x)$ adalah polinomial dan $q(x) \neq 0$.

(2) Persamaan Transenden.

Fungsi transenden atau fungsi non-aljabar adalah fungsi yang tidak dapat dinyatakan dalam operasi aljabar. Fungsi transenden terdiri dari fungsi eksponensial, fungsi logaritmik, fungsi trigonometrik dan fungsi hiperbolik.

\subsection{Akar}

Bilangan $\mathrm{r}$ disebut akar dari suatu persamaan polinomial $f(x)=0$ jika dan hanya jika $f(r)=0$. Berikut ini diberikan teorema lokasi akar :

Teorema 2.1. [1] Misalkan $I=[\alpha, \beta]$ adalah suatu interval dan misalkan $f: I \rightarrow$ $R$ kontinu di I. Jika $\alpha<\beta$ adalah bilangan-bilangan pada I sedemikian sehingga $f(\alpha)<0<f(\beta)$, maka terdapat suatu bilangan $c \in[\alpha, \beta]$ sedemikian sehingga $f(c)=0$.

\subsection{Metode Pencarian Akar}

Secara umum, metode pencarian akar tersebut terbagi atas dua, yaitu:

(1) Metode Tertutup (Bracketing Method).

Dalam proses pencarian akar, metode ini menggunakan selang tertutup $[a, b]$ sebagai lokalisasi akarnya. Dalam selang tersebut dapat dipastikan minimal terdapat satu buah akar. Ada dua metode yang termasuk ke dalam metode tertutup, yaitu metode bagi dua dan metode regula-falsi.

(2) Metode Terbuka (Opened Method).

Dalam metode ini diperlukan tebakan awal akar. Hampiran akar didasarkan pada hampiran akar sebelumnya melalui prosedur iterasi. metode yang termasuk ke dalam metode terbuka adalah metode iterasi Titik Tetap, metode Newton-Rhapson dan metode Secant.

\subsection{Deret Taylor}

Approksimasi orde ke-0 dilakukan dengan mengambil satu suku pertama, yaitu nilai sebelumnya [8].

$$
f\left(x_{i+1}\right)=f(x)
$$

Approksimasi orde ke-1 dilakukan dengan menambah suku lainnya.

$$
f\left(x_{i+1}\right)=f(x)+f^{\prime}\left(x_{i}\right)\left(x_{i+1}-x_{i}\right)
$$

Kemudian dengan menambahkan suku berikutnya diperoleh approksimasi orde ke2, yaitu :

$$
f\left(x_{i+1}\right)=f(x)+f^{\prime}\left(x_{i}\right)\left(x_{i+1}-x_{i}\right)+\frac{f^{\prime \prime}\left(x_{i}\right)}{2 !}\left(x_{i+1}-x_{i}\right)^{2}
$$


Sehingga deret Taylor selengkapnya dapat ditulis sebagai berikut :

$$
\begin{aligned}
f\left(x_{i+1}\right)= & f(x)+f^{\prime}\left(x_{i}\right)\left(x_{i+1}-x_{i}\right)+\frac{f^{\prime \prime}\left(x_{i}\right)}{2 !}\left(x_{i+1}-x_{i}\right)^{2} \\
& +\frac{f^{\prime \prime \prime}\left(x_{i}\right)}{3 !}\left(x_{i+1}-x_{i}\right)^{3}+\ldots+\left(x_{i+1}-x_{i}\right)^{n}+R_{n}
\end{aligned}
$$

dimana

$$
R_{n}=\frac{f^{n+1}(\xi)}{(n+1) !}\left(x_{i+1}-x_{i}\right)^{n+1}
$$

Kemudian deret Taylor dapat ditulis sebagai:

$$
\begin{aligned}
f\left(x_{i+1}\right)= & f(x)+f^{\prime}\left(x_{i}\right) h+\frac{f^{\prime \prime}\left(x_{i}\right)}{2 !} h^{2}+\frac{f^{\prime \prime \prime}\left(x_{i}\right)}{3 !} h^{3} \\
& +\ldots+\frac{f^{n}\left(x_{i}\right)}{n !} h^{n}+R_{n}
\end{aligned}
$$

dengan suku sisa:

$$
R_{n}=\frac{f^{n+1}(\xi)}{(n+1) !} h^{n+1}
$$

\subsection{Metode Newton}

Misalkan $x_{0}$ adalah taksiran untuk $r$ dan misalkan $r=x_{0}+h$. Karena akar sebenarnya adalah $r$ dan $h=r-x_{0}$, maka bilangan atau nilai $h$ menunjukkan seberapa jauh taksiran $x_{0}$ dari nilai yang sebenarnya [4]. Karena $h$ kecil, maka aproksimasi linear (garis tangen) dapat digunakan sehingga:

$$
\begin{aligned}
0 & =f(r)=f\left(x_{0}+h\right) \approx f\left(x_{0}\right)+h f^{\prime}\left(x_{0}\right) \\
h & =-\frac{f\left(x_{0}\right)}{f^{\prime}\left(x_{0}\right)} \\
r-x_{0} & =-\frac{f\left(x_{0}\right)}{f^{\prime}\left(x_{0}\right)} \\
r & =x_{0}-\frac{f\left(x_{0}\right)}{f^{\prime}\left(x_{0}\right)}
\end{aligned}
$$

dan estimasi $x_{1}$ untuk $r$ diberikan oleh :

$$
x_{1}=x_{0}-\frac{f\left(x_{0}\right)}{f^{\prime}\left(x_{0}\right)}
$$

dengan cara yang sama, estimasi $x_{2}$ dapat diperoleh dari $x_{1}$ untuk $r$,yaitu:

$$
x_{2}=x_{1}-\frac{f\left(x_{1}\right)}{f^{\prime}\left(x_{1}\right)}
$$

selanjutnya, jika $x_{n}$ adalah taksiran pada iterasi ke $n$, maka taksiran selanjutnya yaitu taksiran ke $n+1$ dapat diberikan oleh:

$$
x_{n+1}=x_{n}-\frac{f\left(x_{n}\right)}{f^{\prime}\left(x_{n}\right)}
$$




\subsection{Galat}

Galat adalah perbedaan nilai dari suatu besaran antara nilai eksak (nilai sebenarnya) dengan nilai hampirannya.

$$
E=x-x^{*}
$$

$x$ adalah nilai eksak dari besaran, $x^{*}$ adalah nilai hampirannya dan $E$ adalah galat mutlak dari $x[3]$.

Pada metode numerik, ada dua sumber galat, yaitu galat pemotongan dan galat pembulatan. Galat pemotongan adalah galat yang timbul akibat pemotongan rumus matematika tertentu untuk menghampiri suatu besaran. Galat pembulatan adalah galat yang timbul akibat pembulatan bilangan.

\section{Proses Konstruksi Formula Metode Iterasi Baru}

Pada bab ini dijelaskan proses konstruksi formula Metode Iterasi Baru yang menggunakan turunan orde pertama. Metode Iterasi Baru yang bertujuan untuk menentukan akar persamaan non linier satu variabel ini, diperoleh dari Ekspansi Taylor dan metode Steffenson. Formula metode Iterasi Baru dapat diperoleh dengan langkah-langkah sebagai berikut.

(1) Mengkonstruksi formula metode Steffenson dengan menggunakan formula metode Newton.

$$
x_{k+1}=x_{k}-\frac{f\left(x_{k}\right)}{f^{\prime}\left(x_{k}\right)}
$$

dan mengganti turunan pertama dengan

$$
f^{\prime}\left(x_{k}\right)=\frac{f\left(x_{k}+f\left(x_{k}\right)\right)-f\left(x_{k}\right)}{f\left(x_{k}\right)}
$$

diperoleh formula metode Steffenson

$$
x_{k+1}=x_{k}-\frac{\left(f\left(x_{k}\right)\right)^{2}}{f\left(x_{k}+f\left(x_{k}\right)\right)-f\left(x_{k}\right)}
$$

(2) Mengkonstruksi Formula Iterasi Ekspansi Taylor.

Ekspansi deret Taylor $f\left(x_{k+1}\right), f^{\prime}\left(x_{k+1}\right), f^{\prime \prime}\left(x_{k+1}\right)$ dituliskan sebagai berikut.

$$
\begin{gathered}
f\left(x_{k+1}\right)=f\left(x_{k}\right)+f^{\prime}\left(x_{k}\right)\left(x_{k+1}-x_{k}\right)+\frac{1}{2} \\
f^{\prime \prime}\left(x_{k}\right)\left(x_{k+1}-x_{k}\right)^{2}+\frac{1}{6} f^{(3)}\left(x_{k}\right) \\
\left(x_{k+1}-x_{k}\right)^{3}+O\left[\left(x_{k+1}-x_{k}\right)^{4}\right] \\
f^{\prime}\left(x_{k+1}\right)=f^{\prime}\left(x_{k}\right)+f^{\prime \prime}\left(x_{k}\right)\left(x_{k+1}-x_{k}\right)+\frac{1}{2} \\
f^{(3)}\left(x_{k}\right)\left(x_{k+1}-x_{k}\right)^{2}+O\left[\left(x_{k+1}-x_{k}\right)^{3}\right] \\
f^{\prime \prime}\left(x_{k+1}\right)=f^{\prime \prime}\left(x_{k}\right)+f^{(3)}\left(x_{k}\right)\left(x_{k+1}-x_{k}\right) \\
+O\left[\left(x_{k+1}-x_{k}\right)^{2}\right]
\end{gathered}
$$


Dengan mengalikan persamaan (3.5) dengan $(-\omega)\left(x_{k+1}-x_{k}\right)$, dimana $\omega$ adalah sebarang parameter dengan $0 \leq \omega \leq 1$, maka diperoleh :

$$
\begin{aligned}
-\omega\left(x_{k+1}-x_{k}\right) f^{\prime}\left(x_{k+1}\right)= & -\omega\left(x_{k+1}-x_{k}\right) f^{\prime}\left(x_{k}\right) \\
& -\omega f^{\prime \prime}\left(x_{k}\right)\left(x_{k+1}-x_{k}\right)^{2} \\
& -\frac{1}{2} f^{(3)}\left(x_{k}\right)\left(x_{k+1}-x_{k}\right)^{3} \\
& +O\left[\left(x_{k+1}-x_{k}\right)^{4}\right] .
\end{aligned}
$$

Selanjutnya kalikan kedua ruas pada persamaan (3.6) dengan $\left(\frac{1}{2} \omega-\frac{1}{6}\right)\left(x_{k+1}-\right.$ $\left.x_{k}\right)^{2}$ sehingga diperoleh :

$$
\begin{aligned}
\left(\frac{1}{2} \omega-\frac{1}{6}\right)\left(x_{k+1}-x_{k}\right)^{2} f^{\prime \prime}\left(x_{k+1}\right) & =\left(\frac{1}{2} \omega-\frac{1}{6}\right)\left(x_{k+1}-x_{k}\right)^{2} f^{\prime \prime}\left(x_{k+1}\right) \\
& +\left(\frac{1}{2} \omega-\frac{1}{6}\right)\left(x_{k+1}-x_{k}\right)^{3} f^{(3)}\left(x_{k}\right) \\
& +O\left[\left(x_{k+1}-x_{k}\right)^{4}\right] .
\end{aligned}
$$

Kemudian ketiga persamaan, yaitu (3.4),(3.7) dan (3.8) dijumlahkan, dan diperoleh :

$$
\begin{aligned}
f & \left(x_{k+1}\right)-\omega\left(x_{k+1}-x_{k}\right) f^{\prime}\left(x_{k+1}\right)+\left(\frac{1}{2} \omega-\frac{1}{6}\right)\left(x_{k+1}-x_{k}\right)^{2} f^{\prime \prime}\left(x_{k+1}\right) \\
= & f\left(x_{k}\right)+\left(x_{k+1}-x_{k}\right) f^{\prime}\left(x_{k}\right)+\frac{1}{2}\left(x_{k+1}-x_{k}\right)^{2} f^{\prime \prime}\left(x_{k}\right) \\
& -\omega\left(x_{k+1}-x_{k}\right) f^{\prime}\left(x_{k}\right)-\omega\left(x_{k+1}-x_{k}\right)^{2} f^{\prime \prime}\left(x_{k}\right) \\
& +\left(\frac{1}{2} \omega-\frac{1}{6}\right)\left(x_{k+1}-x_{k}\right)^{2} f^{\prime \prime}\left(x_{k+1}\right)+O\left[\left(x_{k+1}-x_{k}\right)^{4}\right] .
\end{aligned}
$$

Selanjutnya dengan mengabaikan $O\left[\left(x_{k+1}-x_{k}\right)\right]^{4}$ dan dengan mengapproksimasi $f^{\prime}\left(x_{k+1}\right)$ dengan $f^{\prime}\left(x_{k}\right)$ dan mengapproksimasi $f^{\prime \prime}\left(x_{k+1}\right)$ dengan $f^{\prime \prime}\left(x_{k}\right)$, maka diperoleh persamaan berikut :

$$
\begin{aligned}
f\left(x_{k+1}\right)= & f\left(x_{k}\right)+\left(x_{k+1}-x_{k}\right) f^{\prime}\left(x_{k}\right) \\
& +\frac{1}{2}\left(x_{k+1}-x_{k}\right)^{2} f^{\prime \prime}\left(x_{k}\right) \\
& -\omega\left(x_{k+1}-x_{k}\right)^{2} f^{\prime \prime}\left(x_{k}\right) . .
\end{aligned}
$$

karena $x_{k+1}$ merupakan akar dari $f(x)=0$ sehingga $f\left(x_{k+1}\right)=0$, maka :

$$
\begin{array}{r}
f\left(x_{k}\right)+\left(x_{k+1}-x_{k}\right) f^{\prime}\left(x_{k}\right)+\frac{1}{2}\left(x_{k+1}-x_{k}\right)^{2} f^{\prime \prime}\left(x_{k}\right)-\omega\left(x_{k+1}-x_{k}\right)^{2} f^{\prime \prime}\left(x_{k}\right)=0 \\
(1-2 \omega) f^{\prime \prime}\left(x_{k}\right)\left(x_{k+1}-x_{k}\right)^{2}+2 f^{\prime}\left(x_{k}\right)\left(x_{k+1}-x_{k}\right)+2 f\left(x_{k}\right)=0 .
\end{array}
$$

Supaya solusi persamaan merupakan bilangan real, maka haruslah $B^{2}-$ $4 A C \geq 0$ sehingga

$$
\begin{aligned}
x_{k+1}-x_{k} & =-\frac{2 f^{\prime}\left(x_{k}\right) \pm \sqrt{\left(2 f^{\prime}\left(x_{k}\right)\right)^{2}-4(1-2 \omega) f^{\prime \prime}\left(x_{k}\right) 2 f\left(x_{k}\right)}}{2(1-2 \omega) f^{\prime \prime}\left(x_{k}\right)} \\
x_{k+1} & =x_{k}-\frac{f^{\prime}\left(x_{k}\right) \pm \sqrt{f^{\prime}\left(x_{k}\right)^{2}-2(1-2 \omega) f^{\prime \prime}\left(x_{k}\right) f\left(x_{k}\right)}}{(1-2 \omega) f^{\prime \prime}\left(x_{k}\right)}
\end{aligned}
$$


Untuk $\omega=0$, maka :

$$
x_{k+1}=x_{k}-\frac{f^{\prime}\left(x_{k}\right) \pm \sqrt{f^{\prime}\left(x_{k}\right)^{2}-2 f^{\prime \prime}\left(x_{k}\right) f\left(x_{k}\right)}}{f^{\prime \prime}\left(x_{k}\right)}
$$

(3) Mengkonstruksi formula Iterasi Baru.

Dengan mengganti turunan dari persamaan (3.2) yaitu

$$
f^{\prime \prime}\left(x_{k}\right)=\frac{f^{\prime}\left(x_{k}+f\left(x_{k}\right)\right)-f^{\prime}\left(x_{k}\right)}{f\left(x_{k}\right)}
$$

maka persamaan (3.11) dapat ditulis menjadi

$$
x_{k+1}=x_{k}-\frac{f\left(x_{k}\right)\left(f^{\prime}\left(x_{k}\right)-\sqrt{f^{\prime}\left(x_{k}\right)^{2}-2\left(f^{\prime}\left(x_{k}+f\left(x_{k}\right)\right)-f^{\prime}\left(x_{k}\right)\right)}\right)}{f^{\prime}\left(x_{k}\right)+f\left(x_{k}\right)-f^{\prime}\left(x_{k}\right)}
$$

\section{Contoh Kasus}

A Contoh 1.

Gunakanlah Metode Iterasi Baru untuk menentukan akar dari $f(x)=x^{2}-$ $\cos x$. Berdasarkan Persamaan maka diperoleh turunan pertama sebagai berikut $f^{\prime}(x)=2 x+\sin x$. Pilih $x_{0}=1$ dan $\epsilon=10^{-100}$ maka diperoleh nilai sebenarnya ,$x=0.82413231230252242296$ yang merupakan salah satu akar dari $f(x)=$ $x^{2}-\cos x$. Hasil iterasi lengkap disajikan dalam tabel berikut.

\begin{tabular}{|c|c|c|c|c|}
\hline $\boldsymbol{n}$ & $\boldsymbol{X}_{\boldsymbol{n}}$ & \multicolumn{1}{|c|}{$\boldsymbol{y}_{\boldsymbol{n}}=\boldsymbol{f}\left(\boldsymbol{X}_{\boldsymbol{n}}\right)$} & $\boldsymbol{Z}_{\boldsymbol{n}}=\boldsymbol{f}^{\prime}\left(\boldsymbol{x}_{\boldsymbol{n}}\right)$ & $\boldsymbol{X}(\boldsymbol{n + 1})$ \\
\hline 0 & 1 & 0.459697694131860282 & 2.8414709848078 & 0.825763854728698 \\
& & 60 & 965066 & 55429 \\
\hline 1 & 0.825763854728698554 & 0.003890263855099659 & 2.3865935963056 & 0.824132313325581 \\
& 29 & 75 & 814676 & 90519 \\
\hline 2 & 0.824132313325581905 & $2.43715619340 \times 10^{-9}$ & 2.3822233576215 & 0.824132312302522 \\
& 19 & & 060690 & 42296 \\
\hline 3 & 0.824132312302522422 & $-1 \times 10^{20}$ & 2.3822233548805 & 0.824132312302522 \\
\hline & 96 & & 311732 & 42296 \\
\hline
\end{tabular}

B Contoh 2 .

Gunakanlah Metode Iterasi Baru untuk menentukan akar dari $f(x)=x^{2}-$ $\exp ^{-x}$. Berdasarkan Persamaan maka diperoleh turunan pertama sebagai berikut $3 x^{2}+\exp ^{-x}$. Pilih $x_{0}=0.5$ dan $\epsilon=10^{-100}$ maka diperoleh nilai sebenarnya,$x=0.77288295914921011285$ yang merupakan salah satu akar dari $f(x)=x^{2}+3 x-1$.

Hasil iterasi lengkap disajikan dalam tabel berikut:

C Contoh 3.

Gunakanlah Metode Iterasi Baru untuk menentukan akar dari $f(x)=x^{2}+3 x-$ 1 Berdasarkan Persamaan maka diperoleh turunan pertama sebagai berikut $f^{\prime}(x)=2 x+3$. Pilih $x_{0}=1$ dan $\epsilon=10^{-100}$ maka diperoleh nilai sebenarnya, $x=0.30277563773199464655$ yang merupakan salah satu akar dari $f(x)=$ $x^{2}+3 x-1$. Hasil iterasi lengkap disajikan dalam tabel berikut. 


\begin{tabular}{|c|c|c|c|c|}
\hline$n$ & $\mathbf{X}_{n}$ & $y_{n}=f\left(x_{n}\right)$ & $Z_{n}=f^{\prime}\left(x_{n}\right)$ & $X(n+1)$ \\
\hline 0 & 0.5 & $\begin{array}{l}-0.4815306597 \\
1263342360 \\
\end{array}$ & $\begin{array}{l}1.3565306597126 \\
334236\end{array}$ & 0.82478891119968917478 \\
\hline 1 & 0.82478891119968917478 & $\begin{array}{l}0.122757209600 \\
70869670 \\
\end{array}$ & $\begin{array}{l}2.4791577528418 \\
991071\end{array}$ & 0.77257668404749131415 \\
\hline 2 & 0.77257668404749131415 & $\begin{array}{l}-0.0006900638 \\
3928838599 \\
\end{array}$ & $\begin{array}{l}2.2524457638479 \\
651739 \\
\end{array}$ & 0.77288295920933860669 \\
\hline 3 & 0.77288295920933860669 & $\begin{array}{l}1.3551305061 \mathrm{x} \\
10^{-10}\end{array}$ & $\begin{array}{l}2.2537243487385 \\
565672 \\
\end{array}$ & 0.77288295914921011286 \\
\hline 4 & 0.77288295914921011286 & $2 \times 10^{-20}$ & $\begin{array}{l}2.2537243484874 \\
829693\end{array}$ & 0.77288295914921011285 \\
\hline 5 & 0.77288295914921011285 & 0 & $\begin{array}{l}2.2537243484874 \\
82969\end{array}$ & 0.77288295914921011285 \\
\hline
\end{tabular}

\begin{tabular}{|c|c|c|c|c|}
\hline $\boldsymbol{n}$ & $\boldsymbol{X}_{n}$ & $\begin{array}{c}\boldsymbol{y}_{n}= \\
\boldsymbol{f}\left(\boldsymbol{X}_{n}\right)\end{array}$ & \multicolumn{1}{|c|}{$\boldsymbol{Z}_{n}=\boldsymbol{f}^{\prime}\left(\boldsymbol{X}_{n}\right)$} & \multicolumn{1}{|c|}{$\boldsymbol{X}(\boldsymbol{n}+1)$} \\
\hline 0 & 1 & 3 & 5 & 0.30277563773199464655 \\
\hline 1 & 0.302775637731994 & $-4 \times 10^{-20}$ & 3.605551275463989293 & 0.30277563773199464655 \\
\hline
\end{tabular}

\section{Penutup}

Berdasarkan hasil yang diperoleh pada bab pembahasan, dapat disimpulkan bahwa:

(1) Metode Iterasi Baru dapat digunakan untuk mencari akar- akar persamaan non linier,dimana galat yang dipilih cukup kecil, yaitu $10^{-100}$.

(2) Algoritma dan proses Metode Iterasi Baru cukup sederhana dan cukup mudah digunakan baik secara manual, maupun dengan perangkat lunak seperti Maple.

\section{Ucapan Terima kasih}

Penulis mengucapkan terima kasih kepada Ibu Dr. Lyra Yulianti, Ibu Dr. Yanita, dan Bapak Budi Rudianto, M.Si yang telah memberikan masukan dan saran sehingga penelitian ini dapat diselesaikan dengan baik.

\section{Daftar Pustaka}

[1] Bartle, R.G. 2000. Introduction to Real Analysis. John Wiley and Sons, Inc. New York.

[2] Chapra S.C and R.P Canale. 2002. Numerical Method For Engineer. McGraw.

[3] Djohan, W. 2005. Diktat MA3171 Metode Numerik. ITB.

[4] Dorn,William. 1986. Studi Kasus Metode Numerik. Jakarta :Erlangga. 
[5] Eskandari, Hamideh. 2009. A new Numerical Solving Method for Equation of One Variable. International Journal of Applied Mathematics and Computer Sciences.

[6] Eskandari, Hamideh. 2009. Numerical Solution of Nonlinier Equation by Using Derivative of First Order. International Journal of Applied Mathematics and Computer Sciences.

[7] Sasongko, Setia B. Metode Numerik dengan Scilab. Yogyakarta :ANDI.

[8] Subakti, I. 2006. Metode Numerik. ITS. 